Jap. J. Physiol., 22, 453-466, 1972

\title{
A NEW METHOD FOR SIMULTANEOUS MEASURE- MENT OF TOTAL RESPIRATORY RESISTANCE AND COMPLIANCE
}

\author{
Yoshimi Miyamoto and Nobuo SaIzen \\ Research Institute of Applied Electricity, Hokkaido University, Sapporo, Japan
}

\begin{abstract}
Summary In a closed lung-box system an equilibration process of unevenly distributed pressure was studied. According to the theoretical analysis of the pressure-time curve, a method of obtaining the resistance and compliance of the lungs and thorax simultaneously from the recorded pressure curve was developed. A 100-liter airtight box was used as a capacity box and the pressure in this box was measured during a passive inhalation process, where the box pressure was increased initially to $10-30 \mathrm{cmH}_{2} \mathrm{O}$. The pressure curve obeyed a simple exponential function of inhalation time; thus, the compliance and resistance were estimated from its time constant and initial box pressure values. The compliance was also calculated from the pressure observed at equilibrium. The compliances obtained at the initial transient and final equilibrium stages were referred to as the dynamic $\left(C_{d}\right)$ and static $\left(C_{s}\right)$ compliances, respectively. Measurements were achieved on eight normal subjects. Although the $C_{d}$ values showed a large dispersion, the mean value obtained in a given subject agreed well with the $C_{s}$ values. On the other hand, the $C_{s}$ values showed a good reproducibility. Mean values for $C_{s}$ and $C_{d}$ were about 0.1 liter $/ \mathrm{cmH}_{2} \mathrm{O}$. The resistance evaluated by dividing the time constant by the compliance of the lung-box system was nearly identical with that measured by the forced oscillation method. The average value was $2.4 \mathrm{cmH}_{2} \mathrm{O} /$ liter/sec.
\end{abstract}

In estimating the work of breathing, total respiratory resistance and compliance are terms of great importance. Up to the present time resistance and compliance have been measured in most cases under different conditions; that is, the former has been measured under static conditions and the latter under dynamic conditions (RoHrer, 1916; RAHN et al., 1946; DuBois et al., 1956). In 1963 MCILROY and his co-workers developed a new method for measuring both resistance and compliance under the same conditions. When a subject

Received for publication September 13, 1971

宮本嘉巳，才善宣雄 
exhales passively without any muscular effort, both the flow and volume curves show a simple exponential decay. In general, both curves have the same time constant. Thus, they measured two pairs of flow and volume curves during expiration, a control curve and a curve with the subject expiring through a known artificial external resistance. By dividing the volume curve by the flow in each case they obtained the time constant. From the two time constants obtained under the two different conditions described above, they calculated the resistance and compliance separately by assuming that the time constant is given by the product of resistance and compliance. Since the above two time constant values were measured under different expiratory conditions, pulmonary resistance and compliance cannot be expected to be constant throughout the measurements. In solving the two simultaneous equations, an error in compliance tends to cause an opposite error in resistance and vice versa, as described by McIlroy et al. Later on, Bergman $(1966,1969)$ attempted to obtain the resistance of an anesthetized subject using a passive exhalation method, measuring the time constant without an artificial resistance and calculating the resistance by dividing the time constant by the compliance measured separately under static conditions. In this case also the same error could be expected.

Recently we developed a new method for obtaining the resistance and compliance simultaneously. A subject inspires air passively from an airtight box of known capacity, containing compressed air. By analyzing the transient and equilibrium box pressure curves from the single inspiration, the resistance and compliance are separated from the time constant. This paper is concerned with this technique, and with the accuracy and reproducibility of these measured values.

\section{METHODS}

1. Principle of the method. In a closed system, namely, an airtight box connected to the lungs through a duct, as shown in Fig. 1, the pressure difference arising between the lungs and the box will diminish after a transient stage, reaching state of equilibrium. The transient change in pressure is generally exponential, and its time constant is related to three terms, namely, the compliances of the respiratory system and the box, and the resistance of the total system. When the box pressure is increased from outside the system and this pressure is released abruptly through the airway into the lungs, the total respiratory compliance and resistance can be evaluated, because the compliance of air in the box is known a priori.

Let the alveolar and box pressures be $P_{2}$ and $P_{1}$, the airflow be $f$, and the resistance be $R$. Then the following relation holds among these parameters:

$$
P_{1}-P_{2}=R f \text {. }
$$


Provided that the box pressure is increased to $P_{0}$ by adding a quantity of air, $V_{0}$, to it prior to the measurement, and that a part of $V_{0}, V_{1}$, is transferred to the lungs after opening the shutter, Eq. (1) is rewritten as follows:

$$
V_{1} / C_{1}=R f+\left(V_{0}-V_{1}\right) / C_{2},
$$

where $C_{1}$ and $C_{2}$ are the compliances of the air in the box and of the respiratory system, respectively. Since the airflow is given by the time derivative of air volume, namely, $f=-d V_{1} / d t$, Eq. (2) can be expressed in relation to $V_{1}$ by following differential equation.

$$
V_{1}\left(1 / C_{1}+1 / C_{2}\right)+R d V_{1} / d t=V_{0} / C_{2}
$$

At $t=0, V_{1}=V_{0}$; thus Eq. (3) is solved as follows:

$$
V_{1}\left(C_{1}+C_{2}\right)=V_{0} C_{2} \exp \left\{-\left(C_{1}+C_{2}\right) t / C_{1} C_{2} R\right\}+V_{0} C_{1} .
$$

Since $V_{0}=P_{0} C_{1}$, the pressure in the box at any time, $P_{1}$, will be given by $V_{1} / C_{1}$. Thus, Eq. (4) can be expressed as follows.

$$
P_{1}\left(C_{1}+C_{2}\right)=P_{0} C_{2} \exp \left\{-\left(C_{1}+C_{2}\right) \mathrm{t} / C_{1} C_{2} R\right\}+P_{0} C_{1} .
$$

At the final stage the first term of the right-hand side of Eq. (5) can be neglected; thus, the total respiratory compliance at this stage can be obtained according to the following simple equation:

$$
C_{2}=C_{1}\left(P_{0}-P_{e}\right) / P_{e}
$$

where $P_{e}$ is the pressure in the box at an equilibrium state. If the compliance at this stage is always identical with that at the transient stage the resistance, $R$, can be obtained by inserting $C_{2}$ of Eq. (6) into Eq. (5). However, since the former compliance differs to some extent from the latter, as described below, it becomes necessary to evaluate the latter value from the $P_{1}$ curve at the transient stage according to Eq. (5). Certainly, Eq. (5) shows that, when the box pressure $P_{1}$ 's are measured at least two points, two unknown factors, $C_{2}$ and $R$, can be estimated by using the measured values for $P_{0}$ and $C_{1}$. However, Eq. (5) is too complicated to use alone for evaluation of $C_{2}$ and $R$ without knowing the final $P_{1}$ value.

Differentiating Eq. (5) we can derive the following equation:

$$
d P_{1} / d t=\left(P_{0} / C_{1} R\right) \exp \left\{-\left(C_{1}+C_{2}\right) t / C_{1} C_{2} R\right\} .
$$

Hence, when $d P_{1} / d t$ is measured at two time points, $t_{1}$ and $t_{2}$, the time constant $C_{1} C_{2} R /\left(C_{1}+C_{2}\right)$ can be obtained from the following equation:

$$
\left(C_{1}+C_{2}\right) / C_{1} C_{2} R=\left\{\ln \left(d P_{1} / d t\right)_{t_{1}}-\ln \left(d P_{1} / d t\right)_{t_{2}}\right\} /\left(t_{2}-t_{1}\right)
$$

Thus, putting the above time constant value into Eq. (5) we can obtain the compliance at the transient stage and then the resistance $R$.

2. Measuring apparatus. The apparatus used is illustrated schematically 


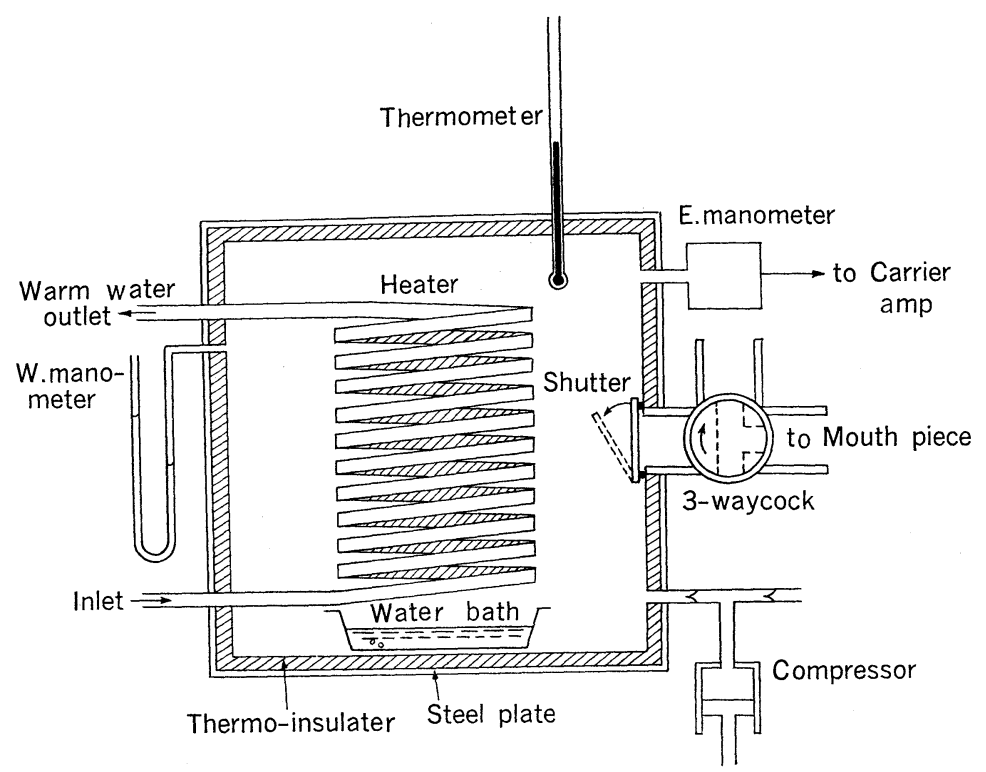

Fig. 1. A schematic diagram of the present measuring apparatus. For explanation, see text.

in Fig. 1. A cubical box $46 \times 46 \times 46 \mathrm{~cm}^{3}$ in size and made of steel plate was used as the airtight box. The spiral tubing shown in the figure was used to maintain the temperature at $37^{\circ} \mathrm{C}$. This tubing was made of copper, and has an inner diameter of $5 \mathrm{~mm}$, through which warm water was circulated from a thermoregulated water bath. In order to keep the temperature in the box as steady as possible, the inner side of the box was covered with a polystyrene sheet $10 \mathrm{~mm}$ thick. To humidify the air in the box a basin containing water at $37^{\circ} \mathrm{C}$ was placed at the bottom. At the front of the box an opening $25 \mathrm{~mm}$ in diameter was connected with a three-way cock. At the inner side of this opening a shutter was installed. The shutter was made of a plexiglass disk $30 \mathrm{~mm}$ in diameter and was designed to open rapidly without any mechanical impact. When it was closed, the box was completely airtight. When the shutter was opened it swung perpendicularly to the flow axis with the aid of an drastic spring, which was triggered by an electromagnet coupled with the three-way cock. After each measurement the shutter was closed manually from the outside of the box with the aid of a lever. The opening time of the shutter was less than $10 \mathrm{msec}$.

At the upper part of the box a strain-gauge-type electromanometer was installed. The measurable maximum pressure of the manometer was $100 \mathrm{cmH}_{2} \mathrm{O}$ and the output signal from it was calibrated by a water manometer mounted on the wall of the box. In order to generate a positive pressure in the box, a known volume of air was introduced from a compressor through an opening at the lower side of the box. The output signal was recorded on a direct writing re- 
corder through a DC amplifier. The compliance of the box, $C_{1}$, was obtained by dividing the volume of air added to the box by the resultant increase in the box pressure. It was 0.083 liter $/ \mathrm{cmH}_{2} \mathrm{O}$.

3. Measuring procedure. The box pressure was first increased by $10-30 \mathrm{~cm}-$ $\mathrm{H}_{2} \mathrm{O}$ by adding about 1 to 3 liters of gas from the compressor. Prior to the pressure measurement the subject breathed room air through the three-way cock. At the end of a normal expiration, when the airflow was stopped, the cock was suddenly turned to connect the lungs with the box. The shutter was simultaneously opened and air flowed into the lungs until the pressure difference between the box and the lungs became zero. The subject was ordered to relax his thorax and not to exert any respiratory effort during the procedure. The pressure change in the box during the passive inhalation was recorded. Figure 2 shows records obtained in a well-trained subject.

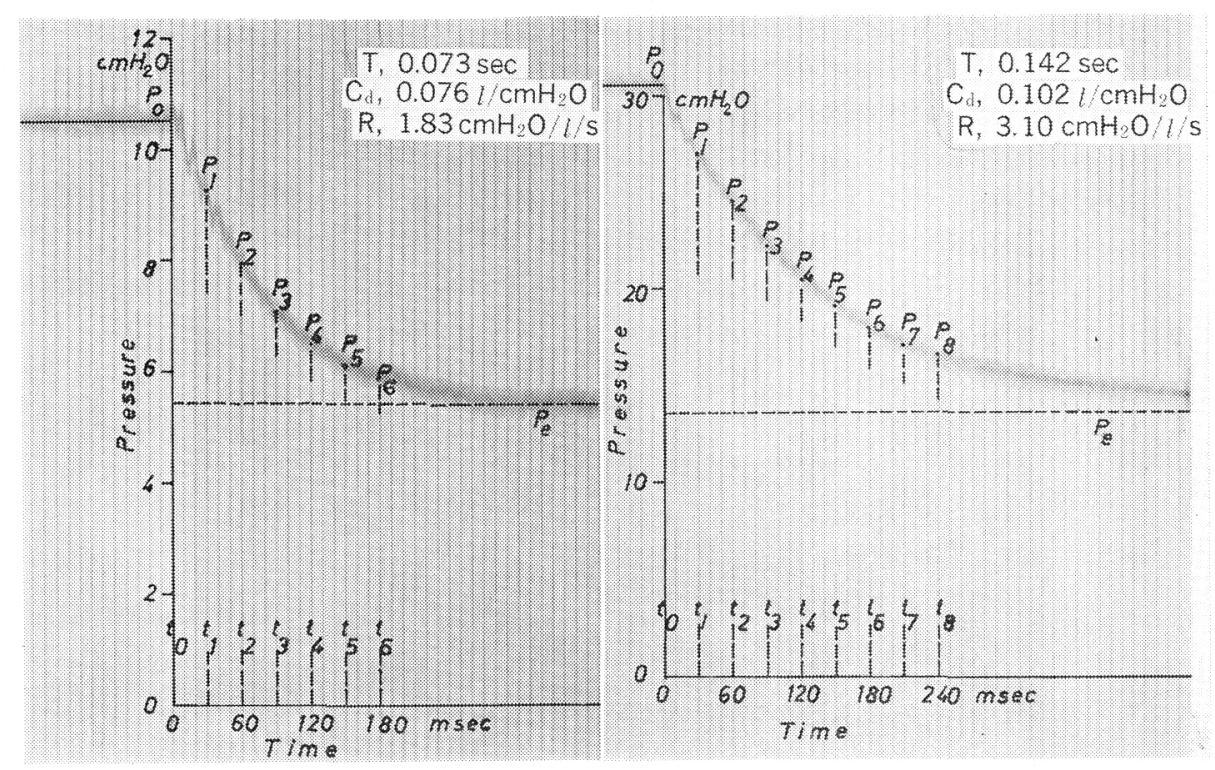

Fig. 2. Actual records of pressure change in the box obtained from a subject. Initial pressures in the box were about $10 \mathrm{cmH}_{2} \mathrm{O}$ (left) and $30 \mathrm{cmH}_{2} \mathrm{O}$ (right). Time cons.ant $(T)$, resistance $(R)$, and dynamic compliance $\left(C_{d}\right)$ calculated from the records are also shown on the right corner of each record.

After the shutter was opened, the box pressure decreased exponentially and reached an equilibrium level within half a second. The equilibrium level was not always distinct because of the movement of the respiratory muscles. Sometimes it fluctuated up and down, especially in the case of nontrained subjects. In such cases the subject was requested after the inhalation maneuver to breathe 
against the box at his normal rate and depth for a minute. The box pressure at the end-expiration should be equal to the equilibrium level of the preceding passive inhalation, if expiration is made without any muscular effort. In fact, in well-trained subjects the equilibrium level of a passive inhalation agreed well with the end-expiratory level of successive breathing.

4. Calculation of the compliance and resistance. The compliance at the final stage, which will be referred to as static compliance, $C_{s}$, was obtained according to Eq. (6) by inserting the measured initial and final pressures $P_{0}$ and $P_{e}$, where $C_{1}$ was 0.083 liter $/ \mathrm{cmH}_{2} \mathrm{O}$.

In order to obtain the compliance at the transient stage, which will be referred to as the dynamic compliance, $C_{d}$, first the time constant $T=C_{1} C_{2} R /\left(C_{1}+C_{2}\right)$ was obtained according to Eq. (8) by subdividing the recorded pressure curve into 5 to 6 sections with equal time intervals of about $30 \mathrm{msec}$. Denoting the pressure decrease at $n$ 'th time interval as $P_{n}$ and the time interval as $t$, Eq. (8) can be rewritten with respect to the time course from the first $n$ 'th section as:

$$
\left(C_{1}+C_{2}\right) / C_{1} C_{2} R=\left(\ln P_{1}-\ln P_{n}\right) /(n-1) t .
$$

Thus, the time constant was calculated by taking the logarithm of the pressure gradient at each section successively and by dividing the difference between its value at any two intervals by the lapse of time. Actually, one section in Eq. (9) was fixed at the first section and the other was subsequently slid from one section to another. The average value on 5 to 6 sections was taken as the actual time factor. By inserting this value into Eq. (5), we calculated $C_{d}$ and then obtained the resistance, $R$, by putting $C_{d}$ into Eq. (9).

In the present study the calculations was performed by a digital computer, HITAC-10 (Hitachi Co., Tokyo). The time required for the calculation was less than $30 \mathrm{sec}$.

\section{RESULTS}

The static and dynamic compliances, $C_{s}$ and $C_{d}$, and resistance, $R$, were measured in 10 normal healthy men. First, the reproducibility of these values was examined through five subsequent measurements on two subjects who were well trained for the present measuring maneuver. Since the mechanical characteristics of the respiratory system are nonlinear, the compliance and resistance may vary with the initial pressure in the box, $P_{0}$. To determine the optimum pressure, which would yield the best reproducibility, the effects of $P_{0}$ on these values were tested at a pressure range of $10-30 \mathrm{cmH}_{2} \mathrm{O}$. Next, at the optimum pressure the measurements were performed on 8 normal subjects who were not trained for the maneuver. Third, the present method was compared with the conventional forced oscillation method with respect to accuracy of the measured resistance values. 


\section{Effect of initial pressure on resistance and compliance values}

Figure 3 shows the relationship between the initial box pressure, $P_{0}$, and its change during inhalation. The ordinate is the logarithm of pressure and the abscissa the time after the shutter is opened. Each point represents the mean of five measurements. The relationship between them was fairly linear for the

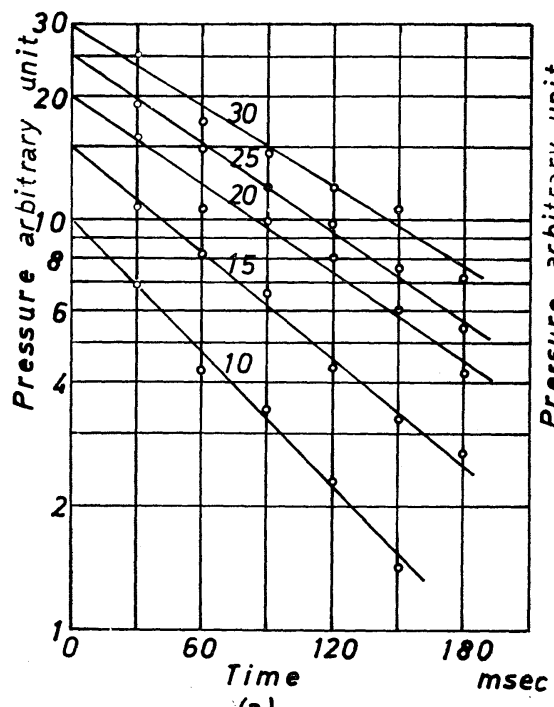

(a)

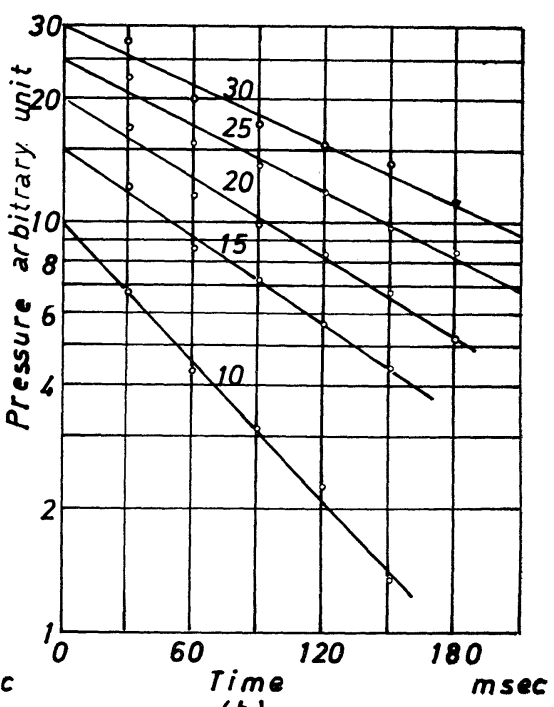

(b)

Fig. 3. Time-pressure relationship of two subjects (a, N.S., b, Y.M.). The ordinate is the logarithm of the pressure and the abscissa, the time after the shutter is opened. Each point represents the mean of five successive measurements. Numbers at each curve indicate the initial pressure in the box.

period of about 1.5 times its time constant (correlation coefficient, - 0.981- 0.996). This means that in a great portion of the time course the box pressure was regarded as an exponential function of time. As the pressure approached an equilibrium point, the pressure curve deviated from the initial exponential curve, suggesting a difference in compliance under dynamic and static conditions. The time constants calculated according to Eq. (9) in subjects N.S. and Y.M. are summarized in Fig. 4. The time constant increased almost linearly with the box pressure in both subjects; the correlation coefficient was 0.909 in N.S. and 0.987 in Y.M. With a twofold increase in pressure, the time constant showed an increase of $30 \%$ in N.S. and $60 \%$ in Y.M. Reproducibility of the measurement was better at lower pressures. At a pressure lower than $15 \mathrm{cmH}_{2} \mathrm{O}$, the percentage standard deviation was about $10 \%$.

The $C_{d}$ and $C_{s}$ values obtained at various box pressures, $P_{0}$, are summarized in Fig. 5. The $C_{d}$ showed a tendency to increase with the $P_{0}$, although the cor- 


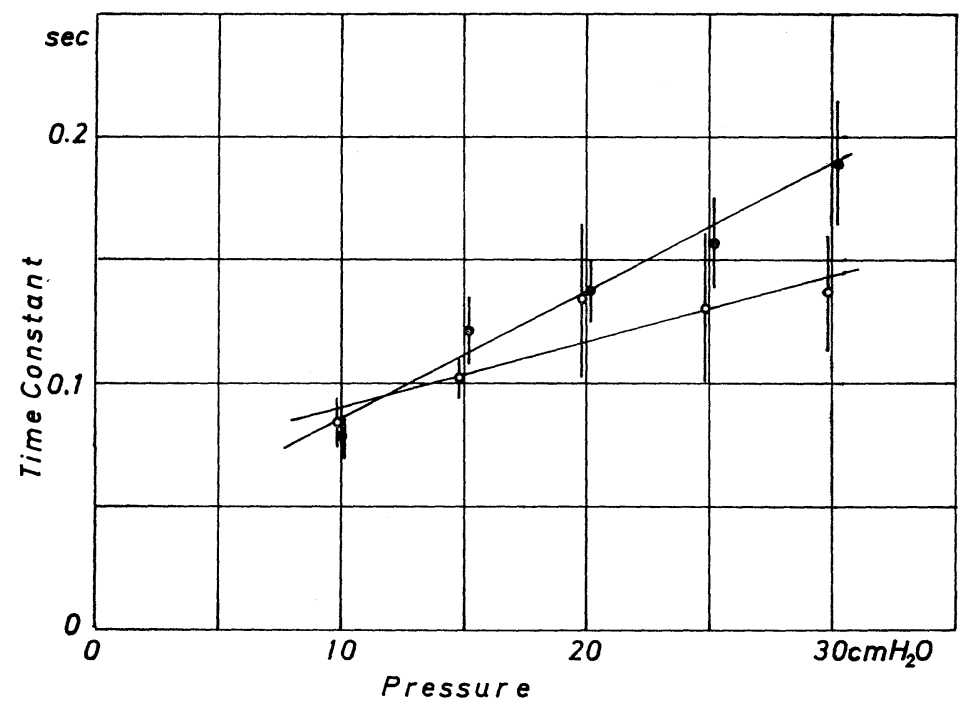

Fig. 4. Effect of the initial pressure on time constants of two subjects. Each point represents the mean of five successive measurements and the bar along the point indicates the standard deviation. Regression lines are $T=0.062+0.0027 P_{0}$ (correlation coefficient $\gamma=0.909)$ for N.S., and $T=0.033+0.0052 P_{0}(\gamma=0.987)$ for Y.M. ○: Sub. N.S.; ๑: Sub. Y.M.

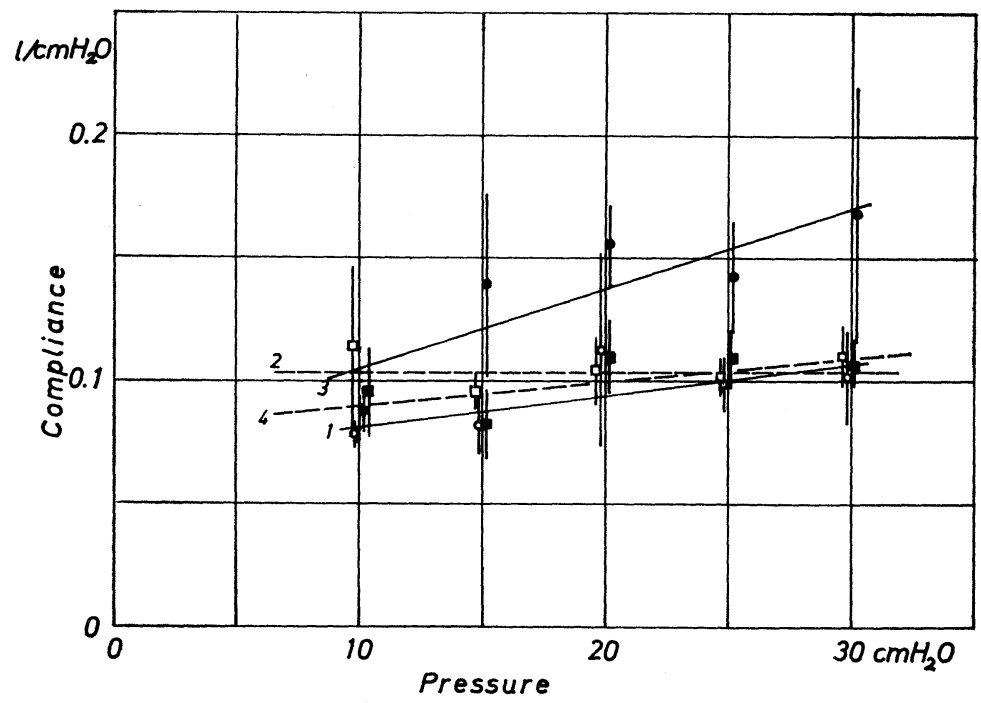

Fig. 5. The effect of the initial pressure on dynamic (circles) and static (squares) compliances of two subjects. Each point represents the mean of five successive measurements and the bar along the point indicates the standard deviation. Regression lines are (1) $C_{d}=0.069+0.0013 P_{0}(\gamma=0.698)$, (2) $C_{s}=0.105$ for N.S., and (3) $C_{d}=0.073$ $+0.0032 P_{0}(\gamma=0.838)$, (4) $C_{s}=0.082+0.0009 P_{0}(\gamma=0.659)$ for Y.M. $\square, \bigcirc$ : Sub. N.S. घ, ๑: Sub. Y.M. 
relation between $C_{d}$ and $P_{0}$ was not significant ( 0.837 in N.S. and 0.698 in Y.M.) The values at 30 and $10 \mathrm{cmH}_{2} \mathrm{O}$ were 0.101 and 0.078 liter/ $\mathrm{cmH}_{2} \mathrm{O}$ (N.S.) and 0.167 and 0.087 liter $/ \mathrm{cmH}_{2} \mathrm{O}$ (Y.M.), respectively. The difference in $C_{d}$ 's between both the above $P_{0}$ 's was statistically significant.

The $C_{s}$ also showed the same dependency on $P_{0}$ as the $C_{d}$, but the effect was less marked. Mean values measured at pressures ranging from 10 to $30 \mathrm{cmH}_{2} \mathrm{O}$ were 0.105 and 0.100 liter $/ \mathrm{cmH}_{2} \mathrm{O}$ in N.S. and Y.M. respectively, which agreed well with those of normal men reported by other workers (NAIMARK and CHERNIACK, 1960; MeAd and Milic-EMili, 1964; CherniaCK and Brown, 1965). MCILroy et al. (1963) reported through the passive exhalation method a value slightly lower than ours $\left(0.080\right.$ liter $\left./ \mathrm{cmH}_{2} \mathrm{O}\right)$.

The reproducibility of $C_{d}$ values was poor, except in the measurements at the lowest pressure; mean percentage standard deviation was about $20 \%$. In contrast, the reproducibility of $C_{s}$ values was better at a higher pressure range. The percentage standard deviation was less than $14 \%$ at pressures exceeding $20 \mathrm{cmH}_{2} \mathrm{O}$. There was no statistically significant difference between the $C_{d}$ and $C_{s}$ values measured at a given $P_{0}$. Reproducibility of the compliance measured by MCILroy et al. (1963) in three subjects with five measurements was reported to be $11-20 \%$ in percentage standard deviation.

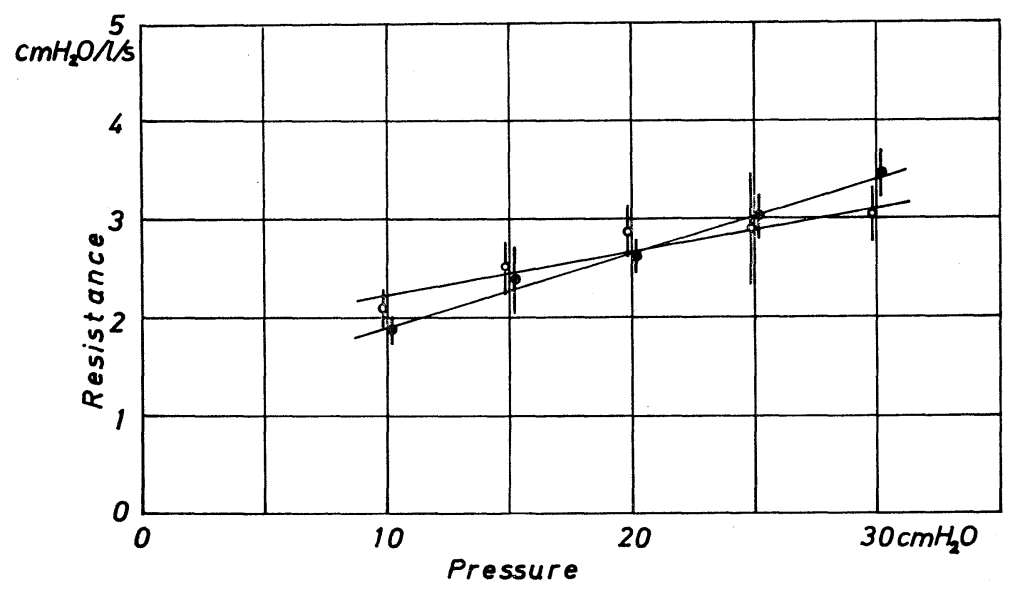

Fig. 6. The effect of the initial pressure on resistance of two subjects. Each point represents the mean of five successive measurements and the bar along the point indicates the standard deviation. Regression lines are $R=1.76+0.045 P_{0}(\gamma=0.948)$ for N.S., and $R=1.14+0.075 P_{0}(\gamma=0.992)$ for Y.M. $\bigcirc$ : Sub. N.S. $\bullet$ : Sub. Y.M.

Resistance, $R$, also showed a tendency to increase with the box pressure, as shown in Fig. 6. This tendency, however, was less marked than that of the constant, since $C_{d}$ also increased with $P_{0}$. The correlation between the $P_{0}$ and $R$ values was highly significant ( $\gamma$ is 0.948 in N.S. and 0.992 in Y.M.). For a 
twofold increase of $P_{0}, R$ increased by $20 \%$ in N.S. and $40 \%$ in Y.M. The values for the resistance $\left(3.02 \mathrm{cmH}_{2} \mathrm{O} /\right.$ liter/sec in N.S. and $3.45 \mathrm{cmH}_{2} \mathrm{O} /$ liter/sec in Y.M. at $30 \mathrm{cmH}_{2} \mathrm{O}$; and $2.09 \mathrm{cmH}_{2} \mathrm{O} /$ liter/sec in N.S. and $1.89 \mathrm{cmH}_{2} \mathrm{O} /$ liter/sec in Y.M. at $10 \mathrm{cmH}_{2} \mathrm{O}$ ) were also on the same order as those of normal men reported by others (Grimby et al., 1968; Fisher et al., 1968; GoldMAN et al., 1970). The difference between $R$ at 30 and at $10 \mathrm{cmH}_{2} \mathrm{O}$ was statistically significant. The resistance values obtained by the passive exhalation method were, however, much higher than ours $\left(5.3 \mathrm{cmH}_{2} \mathrm{O} /\right.$ litler/sec by McIlroy et al., 1963, and 5.5 $\mathrm{cmH}_{2} \mathrm{O} /$ liter/sec by BERGMAN, 1966).

Mean percentage standard deviation throughout all measurements of the $C_{d}$ was $18 \%$ in N.S. and $19 \%$ in Y.M. Mean percentage standard deviation in the $R$ measurements was $12 \%$ in N.S. and $9 \%$ in Y.M. The latter values were even lower than the deviation for the time constant, these values being $17 \%$ in N.S. and $11 \%$ in Y.M. This result may prove to be an advantage of the present method in that the error in the compliance measurement does not exert any influence on the resistance measurement. The reproducibility of the resistance measured by the passive exhalation method was reported to be on the same order as that of the present compliance measurement (McIlroy et al., 1963).

\section{Compliance and resistance in normal subjects}

In the above basic experiments it was clarified that the time constant and its two components, $R$ and $C_{d}$, can be measured with a high reproducibility when $P_{0}$ is $10-15 \mathrm{cmH}_{2} \mathrm{O}$. From a physiological point of view it was also considered to be desirable to measure them at a low $P_{0}$. Measurements were thus performed on 8 untrained subjects with a $P_{0}$ of about $10 \mathrm{cmH}_{2} \mathrm{O}$. On each subject at least five successive measurements were carried out. Examining the correlation between the logarithm of pressure and the inhalation time, the best two measurements were selected for each subject. The measured values are summarized in Table 1. Mean $R$ and mean $C_{d}$ of the 8 subjects were $2.44 \mathrm{cmH}_{2} \mathrm{O} /$ liter/sec and 0.109 liter $/ \mathrm{cmH}_{2} \mathrm{O}$, respectively.

In 4 of the 8 subjects the $C_{s}$ was also measured at $P_{0}$ values of 10 and $20 \mathrm{~cm}$ $\mathrm{H}_{2} \mathrm{O}$. The mean values of these were 0.104 and 0.113 liter $/ \mathrm{cmH}_{2} \mathrm{O}$ with standard errors of 0.009 and 0.011 liter $/ \mathrm{cmH}_{2} \mathrm{O}$, respectively.

\section{Comparison of the resistance measured by the present method and the forced oscillation method}

The resistance of the 8 subjects was measured by the forced oscillation method as well as by the present method. The apparatus consisted of a pressure generator made of a loud speaker $20 \mathrm{~cm}$ in diameter driven at a frequency of $1-10 \mathrm{c} / \mathrm{sec}$, a pneumotachograph, and an electromanometer (Nihon Kohden Co., Tokyo). The speaker was connected to the subjects airway through a mouthpiece. To facilitate breathing, a small bypass tubing was prepared between the speaker and 
Table. 1. Resistance and compliance of 8 normal subjects measured at a pressure of $10 \mathrm{cmH}_{2} \mathrm{O} . \quad T$, time constant of the box and the respiratory system; $C_{d}$, dynamic compliance; $R(\mathrm{p})$, resistance measured by the present method; and $R(\mathrm{o})$, resistance measured by the forced oscillation method.

\begin{tabular}{|c|c|c|c|c|}
\hline Subject & $\begin{array}{c}T \\
\sec \end{array}$ & $\begin{array}{c}C_{d} \\
\text { liter } / \mathrm{cmH}_{2} \mathrm{O}\end{array}$ & \multicolumn{2}{|c|}{$\mathrm{cmH}_{2} \mathrm{O} /$ liter $/ \mathrm{sec}$} \\
\hline K.F. & $\begin{array}{l}0.115 \\
0.131\end{array}$ & $\begin{array}{l}0.116 \\
0.155\end{array}$ & $\begin{array}{l}2.37 \\
2.42\end{array}$ & 2.85 \\
\hline N.I. & $\begin{array}{l}0.127 \\
0.111\end{array}$ & $\begin{array}{l}0.134 \\
0.098\end{array}$ & $\begin{array}{l}2.48 \\
2.48\end{array}$ & 2.40 \\
\hline Y.K. & $\begin{array}{l}0.148 \\
0.111\end{array}$ & $\begin{array}{l}0.157 \\
0.124\end{array}$ & $\begin{array}{l}2.73 \\
2.23\end{array}$ & 2.75 \\
\hline T.K. & $\begin{array}{l}0.120 \\
0.098\end{array}$ & $\begin{array}{l}0.142 \\
0.129\end{array}$ & $\begin{array}{l}2.30 \\
1.94\end{array}$ & 1.60 \\
\hline S.M. & $\begin{array}{l}0.097 \\
0.119\end{array}$ & $\begin{array}{l}0.057 \\
0.070\end{array}$ & $\begin{array}{l}2.88 \\
3.12\end{array}$ & 2.80 \\
\hline A.S. & $\begin{array}{l}0.087 \\
0.120\end{array}$ & $\begin{array}{l}0.101 \\
0.153\end{array}$ & $\begin{array}{l}1.91 \\
2.25\end{array}$ & 2.50 \\
\hline H.K. & $\begin{array}{l}0.116 \\
0.078\end{array}$ & $\begin{array}{l}0.098 \\
0.051\end{array}$ & $\begin{array}{l}2.59 \\
2.45\end{array}$ & 2.05 \\
\hline J.K. & $\begin{array}{l}0.103 \\
0.101 \\
\end{array}$ & $\begin{array}{l}0.076 \\
0.089 \\
\end{array}$ & $\begin{array}{l}2.59 \\
2.34 \\
\end{array}$ & $2.6 ?$ \\
\hline Mean & 0.111 & 0.109 & 2.44 & 2.44 \\
\hline S.D. & 0.017 & 0.035 & 0.31 & 0.43 \\
\hline S.E. & 0.004 & 0.009 & 0.08 & 0.15 \\
\hline
\end{tabular}

the airway. This did not alter the frequency characteristics of the system. The flow through the airway and the mouth pressure were measured simultaneously and displayed on $\mathrm{X}$ and $\mathrm{Y}$ axes of an oscilloscope. The slope of a Lissajous pattern at a resonant frequency indicated the resistance of the respiratory system. The resonant frequency of the present 8 subjects was $5.5 \mathrm{c} / \mathrm{sec}$ (mean) and the peak flow at the frequency was about $0.5 \mathrm{liter} / \mathrm{sec}$. The measurement was achieved at the functional residual capacity. The resistance values measured are also shown in Table 1 (mean of the two successive measurements). The mean value of the 8 subjects was $2.44 \mathrm{cmH}_{2} \mathrm{O} /$ liter/sec, which was not significantly different from that measured by the passive inhalation method described in the present study.

\section{DISCUSSION}

The passive exhalation method of MCILroy et al. (1963) is based on the assumption that respiratory resistance and compliance are not altered by adding external resistance. Since a slight narrowing of the glottis may produce a significant increase in airway resistance and an incomplete relaxation of the thorax may alter the compliance value, the above assumption may not always be valid. When the resistance and compliance are evaluated from two time constant values obtained successively by separate exhalation maneuvers, an error in one component of the time constant causes an opposite error in the other component. 
In contrast, in the present method both the resistance and compliance were obtained in one passive inhalation process. Therefore, any error arising in the measurement remained independent for the two components, resistance and compliance. This was proved experimentally by the fact that the resistance could be obtained with high reproducibility in spite of high variability of the measured compliance values.

The $C_{d}$ values dispersed considerably at a high $P_{0}$ range. This may be explained by the fact that the chest wall was not completely relaxed during the passive inhalation, which resulted in a change in elasticity of the respiratory system. On the other hand, the $C_{s}$ values were fairly reproducible as compared with those obtained by other methods, such as the relaxation pressure method of RAHN et al. (1946). This seems to suggest that the elasticity of the respiratory system is essentially invariable in a completely relaxed state. Though the individual $C_{d}$ values were considerably scattered, the mean $C_{d}$ value showed a good agreement with the $C_{s}$ values and also with the normal values obtained by other authors under static conditions (RAHN et al., 1946; NAIMARK and CHERNIACK, 1960). This result may also be explained by the above fact.

In the passive inhalation method the total gas volume transferred from the box to the lungs was approximately 0.5 liter and the maximum flow rate was about 4 liter sec. On the other hand, the peak flow generated by the forced oscillation method was about $0.5 \mathrm{liter} / \mathrm{sec}$. Despite a significant difference in flow rate between these two methods, a good agreement was observed in the measured resistance values. This evidence suggests that the resistance of the lungs and thorax is practically constant over a wide range of flow rates. The resistance values measured by other researchers using the oscillation method Fisher et al., 1968; Grimby et al., 1968; GoldmAn et al., 1970) are almost comparable with those obtained by the present passive inhalation method, although the former values were measured at a flow rate of about $0.5 \mathrm{liter} / \mathrm{sec}$.

The resistance values measured by the passive exhalation method, however, are about twice as high as the above values. It is well known that the airway resistance is higher during expiration than during inspiration. However, the difference is usually less than $10 \%$ in quiet breathing (FerRIs et al., 1964). In order to clarify the discrepancy between the resistance values obtained by the passive inhalation and exhalation methods, we have attempted to measure the resistance during the passive exhalation by using the same apparatus. Prior to the measurement a subject inspired air from his FRC level by 1 to 2 liters. Then, the initial pressure, $P_{0}$, was measured at the mouth by opening the glottis against the closed shutter of the box. After opening the shutter, the box pressure was measured continuously along the expiration time. In this measurement the box pressure deviated greatly from a simple exponential curve; thus, the time constant was difficult to obtain.

Taking into account the fact that the volume or flow curve obtained by 
MCILroy et al. (1963) during passive exhalation was exponential, it seems possible that the exhalation process was not performed completely when the air was expired against the closed box. This means that the respiratory muscle exerted force to expel the alveolar air into the box. The main difference between Mcllroy's method and the present method consists in whether or not the mouth pressure increases as the alveolar air is expired. Therefore, it is conceivable that an increase of the mouth pressure causes reflex contraction of the respiratory muscle. In general, mouth pressure increases when alveolar air is expired through an artificial external resistance. Hence, it is possible that, when air is expired through external resistance, the respiratory muscles exert a contractile pressure on the thorax, that is, expiration is not completely passive. In such a case, the expiration time is shortened, and the time constant therefore becomes smaller than the expected value.

If such a reflex contraction occurs only when the external resistance is connected to the mouth, the airway resistances calculated from the pressure-time curves obtained with and without the external resistance will differ, as has already been observed in the data of Mcllroy et al. (1963). In the measurement of McILroy et al. the airway resistance is calculated according to the following formula:

$$
R=R_{0} T_{1} /\left(T_{2}-T_{1}\right),
$$

where $R_{0}$ is the external resistance, and $T_{2}$ and $T_{1}$ are time constants measured with and without the external resistance, respectively. Consequently, if $T_{2}$ is reduced more than the predicted value, $R$ will become greater.

Another factor that enhances the resistance in expiration may be a check valve phenomenon. During expiration the alveolar pressure increases; this consequently exerts a greater or lesser force on the airway duct from the outside to narrow the inside space of the duct. When the pressure difference between the outside and inside of the wall exceeds some critical point, the airway will collapse. When the exhalation is made slowly, the pressure difference may not increase to the point where the duct is collapsed. However, when the difference is increased by a sudden change of the mouth pressure, the influence of the compressing force will become significant. In any event, the passive expiration technique seems to be inferior to the passive inhalation technique for obtaining a reliable value for the resistance.

The present method also has sources of error. The glottis is apt to close because of the impact of a sudden inflow of air when the initial pressure is higher than $15 \mathrm{cmH}_{2} \mathrm{O}$. The closing reflex, however, rarely disturbs the measurement since the box pressure is normally set at a range between 10 and $15 \mathrm{cmH}_{2} \mathrm{O}$. The method requires a complicated calculation for determining the time constant, in contrast to the simple method of McIlroy et al. (1963). If a digital computer and an A-D converter are available, this time-consuming calculation can be 
greatly reduced. The main criticism of the present method is that it can give only the resistance during inspiration. From a clinical view point, expiratory resistance measurements are more desirable.

In many patients with obstructive pulmonary diseases, the compliance tends to increase along with the resistance. Therefore, to estimate the total respiratory work, both terms are necessary. Since the compliance and resistance have not been simultaneously measured by other methods as yet, this method may be useful in determining respiratory work conveniently.

The authors wish to express their sincere thanks to Professor Masaji Mochizuki for his valuable comments and revisions of the manuscript. They are also grateful to Mr. Yoshio Shindo and Mr. Takashi Arai for their technical assistance.

\section{REFERENCES}

Bergman, N. A. (1966) Measurement of respiratory resistance in anesthetized subjects. $J$. Appl. Physiol., 21: 1913-1917.

Bergman, N. A. (1969) Properties of passive exhalations in anesthetized subjects. Anesthesiology, 30: 378-387.

Cherniack, R. M. and Brown E. (1965) A simple method for measuring total respiratory compliance: Normal values for males. J. Appl. Physiol., 20: 87-91.

DuBois, A. B., Brody, A. W., Lawis, D. H., and Burgess, B. F., Jr. (1956) Oscillation mechanics of lungs and chest in man. J. Appl. Physiol., 8: 587-594.

FerRis, B. G., Jr., MEAD, J., and OpIE, L. H. (1964). Partitioning of respiratory flow resistance in man. J. Appl. Physiol., 19: 653-658.

Fisher, A. B., DuBois, A. B., and Hyde, R. W. (1968) Evaluation of the forced oscillation technique for determination of resistance to breathing. J. Clin. Invest., 47: 2045-2057.

Goldman, M., Knudson, R. J., Mead, J., Peterson, N., Schwaber, J. R., and Wohl, M. E. (1970) A simplified measurement of respiratory resistance by forced oscillation. J. Appl. Physiol., 28: 113-116.

Grimby, G., Takishima, T., Graham, W., Mackelem, P., and Mead, J. (1968) Frequency dependence of flow resistance in patients with obstructive disease. J. Clin. Invest., 47: 14551465.

McIlroy, M. B., Tierney, D. F., and Nadel, J. A. (1963) A new method for measurement of compliance and resistance of lungs and thorax. J. Appl. Physiol., 18: 424-427.

MeAD, J. and Milic-Emili, J. (1964) Theory and methodology in respiratory mechanics with glossary of symbols. In Handbook of Physiology, Sec. 3, Respiration, ed. by FenN, W. O and RAHN, H. American Physiological Society, Washington, D. C., Vol. 1, pp. 363-376.

NAImARK, A. and Cherniack, R. M. (1960) Compliance of the respiratory system and its com ponents in health and obesity. J. Appl. Physiol., 15: 377-382.

Rahn, H., Otis, A. B., Chadwick, L. E., and Fenn, W. O. (1946) The pressure-volume diagram of the thorax and lung. Am. J. Physiol., 146: 161-178.

RoHreR, E. (1916) Der Zusammenhang der Atemkräfte und ihre Abhängigkeit vom Dehnungszustand der Atemungsorgane. Arch. Ges. Physiol., 165: 419-444. 